\title{
Development of optimum preparation conditions of Fe-deficient M-type Ca-Sr System hexagonal ferrites
}

Ching-Chien Huang ( $\nabla$ feldhuang@hotmail.com )

China Steel Corp https://orcid.org/0000-0002-6924-6717

Mo Chin-Chieh

Himag Magnetic Corp.

Hsiao Tsung-Han

MagnPower Corp.

Lu Sheng-Han

DXC Technology Services LLC

Tai Yen-Hua

DXC Technology Services LLC

Hsu Hsiao-Hsuan

National Taipei University of Technology

Cheng Chun-Hu

National Taiwan Normal University

\section{Research Article}

Keywords: circular economy, by-product, iron oxide powder, hard ferrite, magnet, motor

Posted Date: July 15th, 2020

DOI: https://doi.org/10.21203/rs.3.rs-42224/v1

License: (c) (i) This work is licensed under a Creative Commons Attribution 4.0 International License.

Read Full License 


\title{
Development of optimum preparation conditions of Fe-deficient $M$-type Ca-Sr System hexagonal ferrites
}

\author{
*Ching-Chien Huang ${ }^{1, *}$, Chin-Chieh Mo ${ }^{2,5}$, Tsung-Han Hsiao ${ }^{3}$, Sheng-Han Lu$^{3}$, \\ Yen-Hua Tai ${ }^{3}$, Hsiao-Hsuan $\mathrm{Hsu}^{4, *}$, Chun-Hu Cheng ${ }^{5, *}$ \\ ${ }^{1}$ China Steel Corporation, Kaohsiung, Taiwan \\ ${ }^{2}$ Himag Magnetic Corporation, Pingtung, Taiwan \\ ${ }^{3}$ MagnPower Corporation, Pingtung, Taiwan \\ ${ }^{4}$ Dep. of Materials \& Mineral Resources Engineering, National Taipei University of \\ Technology, Taipei, Taiwan \\ ${ }^{5}$ Dep. of Mechatronic Engineering, National Taiwan Normal University, Taipei, Taiwan
}

\begin{abstract}
In this work, an experiment was carried out to investigate the preparation condition of anosotropic Fe-deficient $M$-type $\mathrm{Ca}$-Sr system ferrite with optimum magnetic and physical properties using the raw material $\mathrm{Fe}_{2} \mathrm{O}_{3}$ from steel industrial iron oxide waste. The compositions of the calcined ferrites were chosen according to the stoichiometry $\mathrm{Ca}_{1-x-y} \mathrm{La}_{x} \mathrm{Sr}_{y} \mathrm{Fe}_{10.9} \mathrm{Co}_{z} \mathrm{O}_{19}$, where $x$ was varied between 0.05 and $0.85, y$ between 0 and 0.18 , and $z=0$. The effect of $\mathrm{CaO}, \mathrm{SiO}_{2}$ and $\mathrm{Co}_{3} \mathrm{O}_{4}$ inter-additives on the $\mathrm{Ca}-\mathrm{Sr}$ system ferrite was
\end{abstract} also discussed in order to obtain low-temperature sintered magnets. The optimum condition of

\footnotetext{
* Corresponding author e-mail address:

feldhuang@hotmail.com (Ching-Chien Huang), chcheng@ntnu.edu.tw (Chun-Hu Cheng), hhhsu@ntut.edu.tw (Hsiao-Hsuan Hsu)
} 
making magnets and some properties of a typical specimen are as follows. The preparation condition: condition: composition $\mathrm{Ca}_{0.37} \mathrm{La}_{0.45} \mathrm{Sr}_{0.18} \mathrm{Fe}_{10.9} \mathrm{Co}_{0} \mathrm{O}_{19}$, calcination condition $1240{ }^{\circ} \mathrm{C}$ $\times 1 \mathrm{hr}$ in atmosphere, low-temperature sintering condition $1210^{\circ} \mathrm{C} \times 1 \mathrm{hr}$ in atmosphere, inter-additives $\mathrm{Co}_{3} \mathrm{O}_{4}=1.85 \mathrm{wt} \%, \mathrm{CaCO}_{3}=1.7 \mathrm{wt} \%, \quad \mathrm{SiO}_{2}=0.6 \mathrm{wt} \%, \mathrm{CaO} / \mathrm{SiO}_{2}=1.59 . \quad$ The magnetic properties of $B_{\mathrm{r}}=5425$ Gauss, ${ }_{\mathrm{b}} H_{\mathrm{c}}=4320 \mathrm{Oe},{ }_{\mathrm{i}} H_{\mathrm{c}}=4602$ Oe and $(B H)_{\max }=5.26 \mathrm{MGOe}$ were obtained for $\mathrm{Ca}-\mathrm{Sr}$ system hard magnets with relatively low cobalt content. The unremarkable steel industrial iron oxide waste is recycled produce high-end permanent magnets under output power $<1 \mathrm{~kW}$, which will eventually be used in high-efficiency motors. This is a specific manifestation of "garbage turning into gold" and is one of the best models of circular economy.

Key words: circular economy; by-product; iron oxide powder; hard ferrite; magnet; motor. 


\section{Introduction}

$M$-type ferrite is an important permanent magnetic material and have been wildly used in many fields of application, including automobile motor, home appliances, actuators, and sensor because of their favor performance/price ratio and excellent chemical stability [1]. Up to now, $M$-type ferrite are still covering more than $50 \%$ of the permanent magnet market, which means any improvement of the properties of $M$-type ferrite is of relevance for the large commercial value. It is intensively required to improve the magnetic properties of $M$-type ferrite in order to decrease the weight of motors used in automobiles and to increase the efficiency of motors. In recent researches, a significant improvement has been obtained in $\mathrm{SrFe}_{12} \mathrm{O}_{19}$ ferrite by combined substitution of $\mathrm{La}^{3+}$ in $\mathrm{Sr}^{2+}$ site and $\mathrm{Co}^{2+}$ in $\mathrm{Fe}^{3+}$, which is related to the increase of the intrinsic magnetic properties, in particular to a drastic change of the magneto-crystalline anisotropy field [2-5]; the simultaneous addition of La and Co can effectively increase the coercivity $\mathrm{i} H_{\mathrm{c}}$ while leaving the remanence $B_{\mathrm{r}}$ unchanged. Presently, $M$-type ferrite hard magnets without cobalt exhibit declining magnetic properties. However, cobalt is critically and strategically important as it is used in association with a broad range of key industrial, sustainable and technological applications. Moreover, following the development of fine particle milling (less than $0.65 \mu \mathrm{m}$ ) and wet magnetic aliment processes provide us good magnetic properties because of single domain particle size after sintering and better orientation, the conventional processing technology has almost reached saturation [5-6]. 
To address above ordeals, it is critical to develop a material formulation with as little cobalt addition as possible for producing $M$-type ferrite hard magnets. In this experiment, we used a cost-effective composition of the calcined ferrites in order to achieve the aforementioned magnetic properties. Our research attempted to study the effect on the magnetic properties of production variables such as the calcination and sintering temperature, the ingredient content of raw material $\mathrm{La}_{2} \mathrm{O}_{3}$ and inter-additives $\mathrm{Co}_{3} \mathrm{O}_{4}, \mathrm{SiO}_{2}$, and $\mathrm{CaCO}_{3}$. Results showed that by optimizing of processing parameters, the magnetic properties were obtained as follows:

$$
B_{\mathrm{r}}=4570 \mathrm{Gauss},{ }_{\mathrm{b}} H_{\mathrm{c}}=4320 \mathrm{Oe},{ }_{\mathrm{i}} H_{\mathrm{c}}=5260 \text { Oe and }(B H)_{\max }=5.16 \text { MGOe. }
$$

\section{Experiment Procedure}

In this work, Fe-deficient $M$-type Ca-Sr system ferrite samples have been synthesized by the conventional ceramic techniques. Nonstoichiometric compositions were chosen to according to the chemical composition $\mathrm{Ca}_{1-x-y} \mathrm{La}_{x} \mathrm{Sr}_{y} \mathrm{Fe}_{10.9} \mathrm{Co}_{z} \mathrm{O}_{19}$, where La content $(x)$ varied between 0.05 and $0.85, \mathrm{Sr}$ content $(y)$ between 0 and 0.18 , and Ca content $(1-x-y)$. The starting materials were $\mathrm{Fe}_{2} \mathrm{O}_{3}, \mathrm{SrCO}_{3}, \mathrm{La}_{2} \mathrm{O}_{3}$ and $\mathrm{CaCO}_{3}$, all of analytical grade except the ferric oxide which was of $98.5 \%$ purity, obtained from the China Steel Plant (CSC, Taiwan) [4-5]. The $\mathrm{SrCO}_{3}$ was $>98 \%$ pure and particle size $2 \sim 3 \mu \mathrm{m}$ from Solvay Barium Strontium GmbH (Germany). Firstly, mixed powders by attritor of the calcination materials prepared by the wet-mixing method were calcined at a heating rate of $10^{\circ} \mathrm{C} / \mathrm{min}$ up to $1220^{\circ} \mathrm{C} \sim 1260^{\circ} \mathrm{C}$ for $1 \mathrm{hr}$ in the air at $10^{\circ} \mathrm{C}$ increments in an electric furnace to obtain strontium ferrite. The calcined 
granules were shattered in a vibration mill to obtain an average particle size of approximately 2.6 $\pm 0.1 \mu \mathrm{m}$. Then $\mathrm{Co}_{3} \mathrm{O}_{4}, \mathrm{CaCO}_{3}$, and $\mathrm{SiO}_{2}$ were added in various concentrations by fine milling the mixture for 9 hours in a stainless steel ball mill (batch size: $400 \mathrm{~g}$ ferrite powder, $9 \mathrm{~kg}$ steel ball (4.76mm diameter), and $700 \mathrm{~g}$ water) before undergoing the sintering. This procedure guarantees a narrow particle size distribution with a mean particle size of approximately $0.75 \mu \mathrm{m}$ measured using a Fisher subsieve sizer (Fisher, USA) which is essential for achieving good magnetic properties. The milled paste was pressed into tablets $\Phi 26.5$ in diameter and $13 \mathrm{~mm}$ height under a magnetic field of 1.5 Telsa and $100 \mathrm{Mpa}$ pressure (based on Japanese Industrial Standard, JIS C2501). The tablets samples were sintering at $1190 \sim 1230^{\circ} \mathrm{C}$ and polished using a grinding machine prior to the measurement of their magnetic parameters $B_{\mathrm{r}}$ and ${ }_{\mathrm{i}} H_{\mathrm{c}}$ using an NIM-2000 HF Hysteresis graph meter (China National Measuring Science Research Institute) at room temperature.

The phase composition of the magnetic powders was characterized by an X-ray diffraction using $\mathrm{Cu} \mathrm{K \alpha}(\lambda=1.5406 \AA)$. Morphologies of the calcined granules, fine milling powder, and sintering tablets of Au-coated samples were observed by a field emission scanning electron microscopy (FE-SEM, Zeiss).

\section{Result and Discussion}

\subsection{Effect of Calcined ferrites Stoichiometry}

As a high-performance sintered permanent ferrite material, lead-acid type ( $M$-type) 
ferrite is now mainly used. $M$-type ferrite is represented by the general formula $A \mathrm{Fe}_{12} \mathrm{O}_{19}$. As an element constituting the $A$ position, $\mathrm{Ba}, \mathrm{Sr}$, or $\mathrm{Ca}$ can be used, and a part of these elements can be replaced by rare earth elements. Simultaneously, a part of Fe can be replaced by Co to achieve higher magnetic properties for reasons of high intrinsic magnetization $M_{\mathrm{s}}$ and anisotropic magnetic field strength $H_{\mathrm{A}}$ [1-3]. On the other hand, for this $M$-type ferrite, the element at the $A$ position could be replaced by another rare earth element La due to the similar radii of $\mathrm{La}^{3+}(1.17 \AA)$ and $\mathrm{Ba}^{2+}(1.22 \AA), \mathrm{Sr}^{2+}(1.32 \AA)$, or $\mathrm{Ca}^{2+}(1.0 \AA)$. La has the highest solid solution limit for $M$-type hexagonal ferrites, and the substitution of $\mathrm{La}$ at the $A$ position could increase the solid content of $\mathrm{Co}$ that replace $\mathrm{Fe}$, which is also conducive to the improvement of overall magnetic properties [1-3]. In this study, a non-stoichiometric formula composed of $\mathrm{Ca}_{1-x-y} \mathrm{La}_{x} \mathrm{Sr}_{y} \mathrm{Fe}_{10.9} \mathrm{Co}_{z} \mathrm{O}_{19}$ was chosen to form Fe-deficient $M$-type Ca-Sr system ferrites with $x=0.45, y=0.18$ and $z=0$. For this formula, $n=10.9$, where $n$ is the molar ratio of $(\mathrm{Ca}+\mathrm{La}+\mathrm{Sr})$ : $(\mathrm{Fe}+\mathrm{Co})$. Among them, no cobalt $(\mathrm{Co})$ element is used in the calcined powder (that is, $z=0$ ), which can reduce the cost of $M$-type ferrite.

The X-ray diffraction patterns of the Fe-deficient $M$-type Ca-Sr system ferrite $\mathrm{Ca}_{1-x-y} \mathrm{La}_{x} \mathrm{Sr}_{y} \mathrm{Fe}_{10.9} \mathrm{Co}_{z} \mathrm{O}_{19}$ calcined powders, where $x$ was varied between 0.05 and $0.85, y$ between 0 and 0.18, and $z=0$, are given in Fig. 1. It can be seen that the XRD patterns of the magnetic powders with La content $(x)=0.05,0.25,0.65$, and 0.85 show either $\alpha-\mathrm{Fe}_{2} \mathrm{O}_{3}$ or $\mathrm{LaFeO}_{3}$ as a second phase, while the calcined powders with La content $(x)=0.45$ is in good 
agreement with the $M$-type strontium ferrite JCPDS card no. 84-1531 and show a single phase hexagonal structure. This result indicates that $\mathrm{La}^{3+}$ ions all substitute the $\mathrm{Sr}^{2+}$ site of the lattice of $M$-type Ca ferrite. The presence of $\alpha-\mathrm{Fe}_{2} \mathrm{O}_{3}$ and $\mathrm{LaFeO}_{3}$ phase for the calcined powders might be attributed to the incomplete reaction under calcination condition. From Fig. 1, all peaks can be ascribed to the $M$-type hexagonal structure with the following Miller indices: (006), (110), (008), (107), (114), and (203). For the magnetic powders with $x$ from 0.05 to 0.85, the first and third strongest peak is (006) and (008), which both are the same family crystal plane as the (001). Because the easy-axis ( $C$-axis) direction of $M$-type $\mathrm{Ca}$-Sr system ferrite is (001), it means that the XRD diffraction peak of the calcined powders can have a higher degree of orientation along the easy axis $\left(f=B_{\mathrm{r}} / J_{\mathrm{s}}\right)[4] . B_{\mathrm{r}} / J_{\mathrm{s}}$ represents the degree of orientation of the sintered magnet, and the value of $J$ is defined as the saturation magnetization $J_{\mathrm{s}}$ on the $J-H$ curve measured by BH Tracer when the applied magnetic field is 796kA/m. As indicated by Lotgering [7] and Kim [8], the magnetic anisotropy was quantitatively expressed by the relative intensity ratio $\left(I_{008} / I_{107}\right)$ between the (008) and (107) diffraction peaks. Fig. 2 represents the relative intensity ratio calculated from the XRD patterns of Calcium System samples. A higher relative intensity ratio $\left(I_{008} / I_{107}\right)$ implies larger anisotropy, thereby leading to a higher degree of orientation along the easy axis $\left(f=B_{\mathrm{r}} / J_{\mathrm{s}}\right)$ and better magnetic properties. The relative intensity ratio $\left(I_{008} / I_{107}\right)$ of randomly oriented ferrite powders was 0.17. For the ferrite $\mathrm{Ca}_{1-x-y} \mathrm{La}_{x} \mathrm{Sr}_{y} \mathrm{Fe}_{10.9} \mathrm{Co}_{z} \mathrm{O}_{19}$ calcined powders, Fig. 2 showed a 
high relative intensity ratio $\left(I_{008} / I_{107}\right)$ of 0.32 at $x=0.45$, suggesting that the specific value of partially substituted amount of $\mathrm{Sr}^{2+}$ by $\mathrm{La}^{3+}$ in the Sr-ferrites leading to no non-magnetic secondary phase could enhance their magnetic properties.

Fig. 3(a) shows an SEM micrograph of ferrite powders of the ferrite $\mathrm{Ca}_{1-x-y} \mathrm{La}_{x} \mathrm{Sr}_{y} \mathrm{Fe}_{10.9} \mathrm{Co}_{z} \mathrm{O}_{19}$ with $\mathrm{Sr}$ addition $(y=0.18)$ calcined at $1260{ }^{\circ} \mathrm{C}$. As seen in Fig. 3(a), these calcined powders are plate shaped with a particle length of $1 \sim 2 \mu \mathrm{m}$, a thickness about $1 \mu \mathrm{m}$ and the aspect ratio (length $\ell /$ thickness $d$ ) $<2$. The shape of these powders is smooth and tends to have a relative hexagonal plate and round shape. However, as shown in Fig. 3(b), the morphology of the ferrite powders of the ferrite $\mathrm{Ca}_{1-x-y} \mathrm{La}_{x} \mathrm{Sr}_{y} \mathrm{Fe}_{10.9} \mathrm{Co}_{z} \mathrm{O}_{19}$ without $\mathrm{Sr}$ addition $(y=0)$ changes from a plate shape into a smaller aspect ratio, and also shows shaped with a particle length of $3 \sim 4 \mu \mathrm{m}$, a thickness about $1 \sim 1.5 \mu \mathrm{m}$ and the aspect ratio (length $\ell /$ thickness d) $>3$. The size of these calcined powders without $\mathrm{Sr}$ tends to have relative coarse powders. The calcined powder used $\mathrm{Sr}$ to replace part of $\mathrm{Ca}$ in this study. As the amount of Ca replaced by $\mathrm{Sr}$ increases from $y=0$ to $y=0.18$, the grain size of the calcined powder decreases and the aspect ratio becomes smaller. This indicates that $\mathrm{Sr}$ inhibits the directional growth of the grains, causing the crystal growth rate in the three-dimensional direction to be nearly uniform during the calcination reaction [1], [3]. These morphological changes may result in the increase in coercivity ${ }_{\mathrm{i}} H_{\mathrm{c}}$ and remanence $B_{\mathrm{r}}$, which could meet the needs of the motor. For the deeper insight into the stoichiometry of $M$-type Ca-Sr system ferrite, a series of samples were 
following prepared with La content $(x)$ varied between 0.05 and 0.85 in step of 0.2 in the formula $\mathrm{Ca}_{1-x-y} \mathrm{La}_{x} \mathrm{Sr}_{y} \mathrm{Fe}_{10.9} \mathrm{Co}_{z} \mathrm{O}_{19}$ at $y=0.18$ and $z=0$.

From the experimental results in Fig. 4, it can be seen that the best $B_{\mathrm{r}}$ and ${ }_{\mathrm{i}} H_{\mathrm{c}}$ can be obtained at $x=0.45$ under the conditions of adding $\mathrm{Co}_{3} \mathrm{O}_{4}=2 \mathrm{wt} \%, \mathrm{CaCO}_{3}=1.57 \mathrm{wt} \%$, and $\mathrm{SiO}_{2}$ $=0.6 \mathrm{wt} \%$ after sintering. If $x$ continues to increase, then $B_{\mathrm{r}}$ and ${ }_{\mathrm{i}} H_{\mathrm{c}}$ will decrease. If the A position in the general formula $\mathrm{AFe}_{12} \mathrm{O}_{19}$ of $M$-type hexagonal ferrite is only $\mathrm{Ca}$, a better $M$-type hexagonal ferrite phase cannot usually be formed. However, by replacing a part of Ca with La element, when $\mathrm{Ca}$ becomes an element constituting A position, a better $M$-type hexagonal ferrite phase can be formed, and then Co can be added after calcination to improve the overall magnetic properties [1]-[3]. The replacement amount of La needs to match the replacement amount of Co. Too much or too little may cause bad adverse effects on the magnetic properties. From the results in Fig. 7, it can be seen that a small amount of $\mathrm{Sr}^{2+}$ enters the $M$-type calcium-based ferrite structure and replaces $\mathrm{Ca}^{2+}$ to produce a substance with a low melting point, which is conducive to the solid-phase reaction and accelerates the densification during the ferrite sintering process. As a result, the density of the material is increased, and the remanence is further increased. However, when too much $\mathrm{Sr}^{2+}$ is added, the grain growth is not uniform, which will cause the intrinsic coercivity of the material to decrease.

To make a small conclusion here, the formula $\mathrm{Ca}_{1-x-y} \mathrm{La}_{x} \mathrm{Sr}_{y} \mathrm{Fe}_{10.9} \mathrm{Co}_{z} \mathrm{O}_{19}$ calcined 
powder was investigated. The results of the study found that when the La replacement amount $x=0.45$, the cobalt-free calcined powder material formula can achieve $100 \% M$-type phase transition at a relative lower calcination temperature, and the absence of $\alpha$ - $\mathrm{Fe}_{2} \mathrm{O}_{3}$ phase and $\mathrm{LaFeO}_{3}$ spinel phases can reach the best relative peak intensity ratio $\left(I_{008} / I_{107}\right)$ and the degree of orientation, so as to obtain better results of magnetic properties such as $B_{\mathrm{r}}$ and ${ }_{\mathrm{i}} H_{\mathrm{c}}$.

\subsection{Optimization of the Calcined temperature}

As can be seen from Fig. 5, the traditional permanent ferrite magnet manufacturing steps are mainly: (1) Weighing and mixing of raw materials $\rightarrow$ (2) Calcination $\rightarrow$ (3) Coarse crushing $\rightarrow$ (4) Fine milling $\rightarrow$ (5) Wet magnetic field pressing $\rightarrow$ (6) Sintering $\rightarrow$ (7) Grinding. At step (1) and (2), the composition and atomic structure of the $M$-type hexagonal ferrite are determined, and the intrinsic magnetic characteristics of the magnet, that is the magnetic field magnetization $\left(J_{\mathrm{S}}\right)$ and the anisotropic magnetic field strength $\left(H_{\mathrm{A}}\right)$ are further established. In step (4), secondary additives $\mathrm{CaCO}_{3}$ and $\mathrm{SiO}_{2}$ will be added after calcination to adjust the magnetic powder grain morphology in the subsequent step (6) sintering reaction and $\mathrm{Co}_{3} \mathrm{O}_{4}$ will be added to further improve $H_{\mathrm{A}}$ of magnet. On the other hand, the coercivity ${ }_{\mathrm{i}} H_{\mathrm{c}}$ is related to the ratio of single magnetic domain grain of the magnetic powder. In order to achieve better magnet characteristics, it is necessary to mill the magnetic powder to an average particle diameter $\left(D_{50}\right)$ of $0.5 \mu \mathrm{m}$ (measured by air permeation method) in a fine milling process to obtain magnetic powder grains in a single magnetic region. In step (5), 
although smaller magnetic particle size can obtain better magnet characteristics, it is not conducive to wet magnetic field pressing, which makes it difficult to drain water during the forming process and easily causes defects such as cracks and ruptures in the green body. From the above (1) (5) process steps, the final $B_{\mathrm{r}}$ and ${ }_{\mathrm{i}} H_{\mathrm{c}}$ of the hard ferrite magnet will be determined, and the relationship between the relevant factors affecting the characteristics and the process is as described in the following equation:

$$
\begin{aligned}
& B_{\mathrm{r}} \propto J_{\mathrm{s}} \times a \times d \times f \\
& { }_{\mathrm{i}} H_{\mathrm{c}}=b \times H_{\mathrm{A}}-N \times\left(B_{\mathrm{r}}+J_{\mathrm{s}}\right) / \mu_{0}
\end{aligned}
$$

In equation (1), $J_{\mathrm{s}}$ is the magnetization of the magnetic field, $a$ is the comparative example of permanent magnet magnetism, and $d$ is the relative density of the sintered magnet (i.e. theoretical density), $f$ is the orientation degree of the grain arrangement in the sintered magnet. $f$ is the degree of orientation of the grain alignment in the sintered magnet, which can be measured from $B_{\mathrm{r}}$ and $J_{\mathrm{s}}$ in the second quadrant of the demagnetization curve $\left(f=B_{\mathrm{r}} / J_{\mathrm{s}}\right)$. In equation (2), $b, H_{\mathrm{A}}, N, B_{\mathrm{r}}$, and $J_{\mathrm{s}}$ are the grain size factor, anisotropic magnetic field strength, grain demagnetization factor, remanence, and magnetization of the magnetic field [1]-[2], [11]. As the particle size of the magnetic powder decreases, the factor $b$ will increase and ${ }_{\mathrm{i}} H_{\mathrm{c}}$ will increase. $N$ is controlled by the shape of the grains, and the closer the grains are to the disc shape, the larger $N$ is. It can also be known from equation (2) that $B_{\mathrm{r}}$ and ${ }_{\mathrm{i}} H_{\mathrm{c}}$ are two magnetic properties in a trade-off state. 
Fig. 6 shows the effect of the calcined temperature, varied between $1220^{\circ} \mathrm{C}$ and $1260^{\circ} \mathrm{C}$ in steps of $20^{\circ} \mathrm{C}$, on the magnetic properties of samples of composition $\left(\mathrm{Ca}_{1-x-y} \mathrm{La}_{x} \mathrm{Sr}_{y} \mathrm{Fe}_{10.9} \mathrm{Co}_{z} \mathrm{O}_{19}\right)$. The remanence $B_{\mathrm{r}}$ values of these powders gradually decrease with increasing calcination temperature, and reach a maximum value at $1240^{\circ} \mathrm{C}$. According to the analysis, when the calcination temperature reaches $1240^{\circ} \mathrm{C}$, the magnetic properties are the best because the reaction is complete. If the calcination temperature is below $1240^{\circ} \mathrm{C}$, unreacted $\mathrm{Fe}_{2} \mathrm{O}_{3}$ may exist due to incomplete calcination reaction, which will affect the magnetic properties. As the calcination temperature increases, the amount of unreacted $\mathrm{Fe}_{2} \mathrm{O}_{3}$ decreases, and $B_{\mathrm{r}}$ increases. When the calcination temperature is higher than $1240^{\circ} \mathrm{C}$, the magnetic characteristics begin to decline, which may be related to the excessive growth of the calcined grains or the melting state during the calcination process. On the other hand, as the calcination temperature increases, the coercivity ${ }_{\mathrm{i}} H_{\mathrm{c}}$ increases first and then decreases. The ${ }_{\mathrm{i}} H_{\mathrm{c}}$ increased from $4882 \mathrm{Oe}$ calcined at $1220^{\circ} \mathrm{C}$ to the peak $5275 \mathrm{Oe}$ calcined at $1240^{\circ} \mathrm{C}$. When the calcination temperature was higher than $1240^{\circ} \mathrm{C},{ }_{\mathrm{i}} H_{\mathrm{c}}$ decreased slowly. As described in equation (2), there are many factors that affect ${ }_{\mathrm{i}} H_{\mathrm{c}}$. It is considered that in this study, the increase in ${ }_{\mathrm{i}} H_{\mathrm{c}}$ of sintered products when calcined at less than $1240^{\circ} \mathrm{C}$ could be considered as the increase in calcination temperature leading to the removal of decreased grain demagnetization factor $N$ or increased anisotropic magnetic field strength $H_{\mathrm{A}}$. For calcination above $1240^{\circ} \mathrm{C}$, the decrease of ${ }_{\mathrm{i}} H_{\mathrm{c}}$ may be caused by abnormal grain growth due to irregular 
melting when the calcination temperature is too high. After considering the characteristics of $B_{\mathrm{r}}$ and ${ }_{\mathrm{i}} H_{\mathrm{c}}$, the calcination temperature used in this research is $1240^{\circ} \mathrm{C}$.

\subsection{Effect of secondary additives on magnetic properties}

For the formula composed of $\mathrm{Ca}_{1-x-y} \mathrm{La}_{x} \mathrm{Sr}_{y} \mathrm{Fe}_{10.9} \mathrm{Co}_{z} \mathrm{O}_{19} \quad(x=0.45, y=0.18)$ chosen in this study, Fig. 7 shows the dependence of the magnetic properties $B_{\mathrm{r}}$ and ${ }_{\mathrm{i}} H_{\mathrm{c}}$ of the fabricated sintered magnet on the amount of $\mathrm{Co}_{3} \mathrm{O}_{4}$ added after calcination. When the amount of $\mathrm{Co}_{3} \mathrm{O}_{4}$ is increased from $1.25 \mathrm{wt} \%$ to $2.50 \mathrm{wt} \%$, better $B_{\mathrm{r}}$ and ${ }_{\mathrm{i}} H_{\mathrm{c}}$ could be achieved when the amount of $\mathrm{Co}_{3} \mathrm{O}_{4}$ is increased to $1.85 \mathrm{wt} \%$. It can also be seen from the results in Fig. 7 that when the amount of $\mathrm{Co}_{3} \mathrm{O}_{4}$ added is too low, both $B_{\mathrm{r}}$ and ${ }_{\mathrm{i}} H_{\mathrm{c}}$ are insufficient. On the other hand, $B_{\mathrm{r}}$ starts to reverse and ${ }_{\mathrm{i}} \mathrm{H}_{\mathrm{c}}$ is saturated when the amount of $\mathrm{Co}_{3} \mathrm{O}_{4}$ added is too high. According to the above experimental results, by using moderate $\mathrm{Co}_{3} \mathrm{O}_{4}$ as inter-additives after calcination, the magnetic characteristics have been significantly improved, mainly because the residual magnetic moment of $\mathrm{Co}^{2+}$ plays an important role in the process of increasing the coercive force [2]. Due to the instability of orbital angular momentum, it is well known that $\mathrm{Co}^{2+}$ changes the anisotropy of magnetic crystals. The high positive value of the anisotropy constant $\left(K_{1}\right)$ of the $\mathrm{Co}_{3} \mathrm{O}_{4}$ trace additive added to the material formula can help $M$-type ferrites achieve better ${ }_{\mathrm{i}} H_{\mathrm{c}}\left({ }_{\mathrm{i}} H_{\mathrm{c}} \propto\left(2 K_{1} / M_{\mathrm{s}}\right)\right)$. Without $\mathrm{Co}_{3} \mathrm{O}_{4}$ in the $M$-type ferrite, the magnetic properties of the permanent ferrite will be difficult to improve. It is important to note that achieving higher $B_{\mathrm{r}}$ is more difficult than achieving higher ${ }_{\mathrm{i}} H_{\mathrm{c}}$. The trace additive $\mathrm{Co}_{3} \mathrm{O}_{4}$ 
participates in the reaction during the sintering process, and also plays a key role in the uniformity of grain growth and sintering densification, which can help the permanent ferrite achieve better $B_{\mathrm{r}}$.

According to the opinions put forward in the previous literature research, $\mathrm{CaCO}_{3}$ and $\mathrm{SiO}_{2}$ inter-additives added during the fine milling stage (i.e. after calcination, refer to section 3.2 step (4)) can form a clear liquid phase at the grain boundaries during the sintering process. The generation state of this liquid phase will depend on the material composition and sintering process conditions [10]-[11]. The influence of $\mathrm{SiO}_{2}$ added during the fine milling stage in this study is effective in suppressing the growth of abnormal magnetic powder grains and increasing ${ }_{\mathrm{i}} H_{\mathrm{c}}$, but it is relatively possibly that the reduction in sintering density will cause further reduction in $B_{\mathrm{r}}[12]$. On the other hand, adding another additive, $\mathrm{CaCO}_{3}$, in the the fine milling stage can promote the anisotropy growth of magnetic powder grains and help densify during the sintering process, so $B_{\mathrm{r}}$ could be improved [5]. From the above results and discussions, it can be known that if two inter-additives, $\mathrm{CaCO}_{3}$ and $\mathrm{SiO}_{2}$, would be added at the same time during the fine milling stage, the grain growth suppression of the basal plane (i.e. $A$-axis and $B$-axis) and promotion of the anisotropic growth parallel to the $C$-axis of the hexagonal calcined powder grain of the orientation magnetic field direction can be adjusted during the sintering process. Generally, by controlling the weight ratio of the inter-additive $\mathrm{CaO} / \mathrm{SiO}_{2}$ added during the fine milling stage to the appropriate range, the purpose of 
simultaneously increasing $B_{\mathrm{r}}$ and ${ }_{\mathrm{i}} H_{\mathrm{c}}$ can be achieved. Fig. 8 shows that for the formula composed of $\mathrm{Ca}_{1-x-y} \mathrm{La}_{x} \mathrm{Sr}_{y} \mathrm{Fe}_{10.9} \mathrm{Co}_{z} \mathrm{O}_{19}(x=0.45, y=0.18)$ of the $M$-type Ca-based permanent ferrite calcined material, the amount of $\mathrm{Co}_{3} \mathrm{O}_{4}$ and $\mathrm{SiO}_{2}$ added during the fine milling stage fixed at $1.85 \mathrm{wt} \%$ and $0.55 \mathrm{wt} \%$, respectively. With the continuous increase of the weight ratio of the inter-additive $\mathrm{CaO} / \mathrm{SiO}_{2}, \quad B_{\mathrm{r}}$ and ${ }_{\mathrm{i}} H_{\mathrm{c}}$ both increased significantly. When $\mathrm{CaO} / \mathrm{SiO}_{2}=1.63$ (i.e., $\mathrm{CaCO}_{3}$ increase to $1.6 \mathrm{wt} \%$ while $\mathrm{SiO}_{2}$ fixed at $0.55 \mathrm{wt} \%$ ), it seems to be very effective for densifying the sintered magnet and uniformizing the particle size distribution of the magnetic powder grains in the sintered magnet. At this time, $B_{\mathrm{r}}$ and ${ }_{\mathrm{i}} H_{\mathrm{c}}$ could reach the best value at the same time [13]. It was also found in Fig.8 that $0.55 \mathrm{wt} \%$ of $\mathrm{SiO}_{2}$ added during the fine milling stage could not sufficiently prevent the grain growth caused by the addition of more $\mathrm{CaCO}_{3}$ in the sintering sample, and therefore also caused the decrease of ${ }_{\mathrm{i}} H_{\mathrm{c}}$. Theoretically, from the foregoing equation (2), it can be known that the ${ }_{\mathrm{i}} H_{\mathrm{c}}$ of $M$-type Ca-based permanent ferrite is affected by many factors, such as sintering powder grain size, sintering powder grain morphology, crystal defects and anisotropic growth of sintering powder grain. Among them, the lower coercive force caused by the higher $\mathrm{CaCO}_{3}$ addition during the fine milling stage may be related to the larger sintering powder grain size and higher growth anisotropy [10]. In addition, the result from Fig. 8 also means that when $\mathrm{CaO} / \mathrm{SiO}_{2}$ increased above 1.63 , both $B_{\mathrm{r}}$ and ${ }_{\mathrm{i}} H_{\mathrm{c}}$ began to show a downward trend at the same time, especially the deterioration of ${ }_{\mathrm{i}} H_{\mathrm{c}}$ was more serious. The main reason is that when 
$\mathrm{CaO} / \mathrm{SiO}_{2}$ is too high (fixed $\mathrm{SiO}_{2}$ addition amount is $0.55 \mathrm{wt} \%$ ), the nonmagnetic phase in the sintering magnet increases, causing $B_{\mathrm{r}}$ to decrease. As mentioned above, due to too high weight ratio of the inter-additive $\mathrm{CaO} / \mathrm{SiO}_{2}$, which leading to the excessive addition of $\mathrm{CaCO}_{3}$, the degree of degradation of ${ }_{\mathrm{i}} H_{\mathrm{c}}$ is therefore more significant than that of $B_{\mathrm{r}}$.

Fig. 9 shows the micromorphology of the ferrite $\mathrm{Ca}_{1-x-y} \mathrm{La}_{x} \mathrm{Sr}_{y} \mathrm{Fe}_{10.9} \mathrm{Co}_{z} \mathrm{O}_{19} \quad(x=0.45$, $y=0.18$ ) magnet calcined at $1240^{\circ} \mathrm{C}$ and sintered at $1230^{\circ} \mathrm{C}$. The crystal grains in the magnet appear plate-like, and the normal direction of tabular crystal grains coincides with the easy magnetization axis ( $C$-axis). The orientation of the pressed oriented magnetic powder is not destroyed during sintering process and has good uniformity of grain size; therefore, the magnetic grains are oriented and grown, resulting in the high properties of the sintering magnet, which is better than traditional La-Ca-Co ferrites [2], [4], [8]-[9], and help to achieve the purpose of large-scale industrial production.

\section{Conclusion}

This study started using with iron oxide powder, a by-product of the cold rolling process of China Steel Corporation (CSC), as the main raw material. It was constructed in order: (1) Low-mole ratio calcined material formula without cobalt (Co) addition to reduce the calcination temperature and simultaneously reaches $100 \% M$-type phase conversion, which can further reduce mass production costs; (2) Optimized the calcination process condition; (3) 
Optimized formulation of inter-additives of $\mathrm{Co}_{3} \mathrm{O}_{4}, \mathrm{CaCO}_{3}, \mathrm{SiO}_{2}$ added during the fine milling stage. Herein, the material formula and process technology of high-performance Fe-deficient $M$-type Ca-Sr system permanent ferrite magnets are successfully established, and the magnetic properties such as $B_{\mathrm{r}}$ and ${ }_{\mathrm{i}} H_{\mathrm{c}}$ are effectively improved. It should be particularly emphasized that the calcined material formula of the Fe-deficient $\mathrm{Ca}$-Sr system permanent ferrite developed by this research does not include the precious metal cobalt, the calcination temperature and sintering temperature are low, and the addition amount of the inter-additive $\mathrm{Co}_{3} \mathrm{O}_{4}$ is small, which overcome high cost technical bottlenecks such as excessive $\mathrm{Co}_{3} \mathrm{O}_{4}$ addition in order to achieve high characteristics in the past, and comprehensively improve magnetic characteristics and production efficiency. Combining above core technologies, this research uses CSC's self-produced iron oxide powder with high impurity content and low specific surface area as the main raw material, and successfully introduced the Fe-deficient $M$-type Ca-Sr system permanent ferrite magnets with excellent magnetic properties, so as to establish the removal channel of steel industrial iron oxide waste; it is one of the best models of circular economy.

\section{Reference}

[1] F. Kools, A. Morel, R Grossinger, et al. LaCo-substituted hexaferrite magnets, a new class of high grade ceramic magnets; intrinsic and microstructural aspects. J. Magn. Magn. Mater. 2002; 242-245: 1270-1276. 
[2] Kikuchi, T., Nakamura, T., Yamasaki, T., Nakanishi, M., Fujii, T., Takada, J., Ikeda, Y., Magnetic properties of La-Co substituted $M$-type strontium hexaferrites prepared by polymerizable complex method. J. Magn. Magn. Mater. 2010; 322: 2381-2385.

[3] A. Morel, F. Kools, P. Tenaud, Modeling of La-Co substituted $M$-type hexaferrite coercivity of $\mathrm{Sr}_{1-x} \mathrm{La}_{x} \mathrm{Fe}_{12-x} \mathrm{Co}_{x} \mathrm{O}_{19}$. ICF-8, Kyoto, Japan; 2000: 434-436.

[4] Ching-Chien Huang, Ai-Hua Jiang, Ching-Hsuan Liou, Yi-Chen Wang, Chi-Ping Lee, Tong-Yin Hung, Chun-Chung Shaw, Yung-Hsiung Hung, Ming-Feng Kuo and Chun-Hu Cheng. Magnetic Property Enhancement of Cobalt-Free M-Type Strontium Hexagonal ferrites by $\mathrm{CaCO}_{3}$ and $\mathrm{SiO}_{2}$ Addition. Intermetallics. 2017; 89: 111-117.

[5] Ching-Chien Huang, Ai-Hua Jiang, Yung-Hsiung Hung, Ching-Hsuan Liou, Yi-Chen Wang, Chi-Ping Lee, Tong-Yin Hung, Chun-Chung Shaw, Ming-Feng Kuo, Chun-Hu Cheng, Influence of $\mathrm{CaCO}_{3}$ and $\mathrm{SiO}_{2}$ Additives on Magnetic Properties of $M$-type Calcium Systems. J. Magn. Magn. Mater. 2018; 451: 288-294.

[6] J. Ding, R. Street, and H. Nishio, Magnetic properties of Ba- and Sr-hexaferrite prepared by mechanical alloying. J. Magn. Magn. Mater., 1996; 164: 385-389.

[7] F. K. Lotgering, Topotactical reactions with ferromagnetic oxides having hexagonal crystal structure, J. Inorg. Nucl. Chem. 1959; 9: 113-123.

[8] Kyumin Kim, Kwang-Won Jeon, Ki Woong Moon, Min Kyu Kang, and Jongryoul Kim, Effects of calcination conditions on magnetic properties in Strontium ferrite synthesized by the molten salt method. IEEE Trans. Magn. 2016; 52: 2101604.

[9] F. Kools, A. Morel, P. Tenaud, La-Co substituted Sr and Ba M-type ferrites magnet properties versus intrinsic and microstructural factors. ICF-8, Kyoto, Japan; 2000: 437-439.

[10] Y. Kaneko, K. Kitajima, and N. Takusagawa, Effects of $\mathrm{CaO}$ and $\mathrm{SiO}_{2}$ addition on the microstructure and intrinsic coercivity of sintered Sr-ferrite. J. Ceram. Soc. Jpn. Intl. Ed. 1992; 100: 1413-1417. 
[11] F. Kools, The action of a silica additive during sintering of strontium Hexaferrite. Sci. Sint. 1985; 17: 49-80.

[12] J. Töpfer, S. Schwarzer, S. Senz, and D. Hesse, Influence of $\mathrm{SiO}_{2}$ and $\mathrm{CaO}$ additions on the microstructure and magnetic properties of sintered Sr-hexaferrite. J. Eur. Ceram. Soc. 2005; $2: 1681-1688$.

[13] Ching-Chien Huang, Ai-Hua Jiang, Yung-Hsiung Hung, Ching-Hsuan Liou, Yi-Chen Wang, Chi-Ping Lee, Tong-Yin Hung, Chun-Chung Shaw, Ming-Feng Kuo, Chun-Hu Cheng, Influence of $\mathrm{CaCO}_{3}$ and $\mathrm{SiO}_{2}$ Additives on Magnetic Properties of $M$-type Calcium Systems. J. Magn. Magn. Mater. 2018; 451: 288-294. 


\section{Figure Captions:}

Fig. 1. X-ray diffraction patterns of the hexaferrite $\mathrm{Ca}_{1-x-y} \mathrm{La}_{x} \mathrm{Sr}_{y} \mathrm{Fe}_{10.9} \mathrm{Co}_{z} \mathrm{O}_{19}$ calcined powders with La content $(x)$ from 0.05 to 0.85 , and Ca content (1- $x-y)$.

Fig.2. Relative intensity ratio $\left(I_{008} / I_{107}\right)$ of the hexaferrite $\mathrm{Ca}_{1-x-y} \mathrm{La}_{x} \mathrm{Sr}_{y} \mathrm{Fe}_{10.9} \mathrm{Co}_{z} \mathrm{O}_{19}$ calcined powders with La content $(x)$ from 0.05 to 0.85 , and Ca content (1- $x-y)$.

Fig.3. SEM of the hexaferrite $\mathrm{Ca}_{1-x-y} \mathrm{La}_{x} \mathrm{Sr}_{y} \mathrm{Fe}_{10.9} \mathrm{Co}_{z} \mathrm{O}_{19}$ calcined powders with $\mathrm{Sr}$ content (y) from 0 to 0.18 .

Fig.4. The dependence of the magnetic properties $B_{\mathrm{r}}$ and ${ }_{\mathrm{i}} H_{\mathrm{c}}$ of the fabricated sintered magnet on the $x$ value of the formula $\mathrm{Ca}_{1-x-y} \mathrm{La}_{x} \mathrm{Sr}_{y} \mathrm{Fe}_{10.9} \mathrm{Co}_{z} \mathrm{O}_{19}$ calcined powder.

Fig.5. Correlation between magnetic characteristics and related factors in the manufacturing process of permanent ferrite magnets.

Fig.6. Effect of the calcination temperature on $B_{\mathrm{r}}$ and ${ }_{\mathrm{i}} H_{\mathrm{c}}$ of the hexaferrite $\mathrm{Ca}_{1-x-y} \mathrm{La}_{x} \mathrm{Sr}_{y} \mathrm{Fe}_{10.9} \mathrm{Co}_{z} \mathrm{O}_{19}(x=0.45, y=0.18)$ calcined powders.

Fig.7. The dependence of the magnetic properties $B_{\mathrm{r}}$ and ${ }_{\mathrm{i}} H_{\mathrm{c}}$ of the fabricated sintered magnet on the amount of $\mathrm{Co}_{3} \mathrm{O}_{4}$ added after calcination.

Fig.8. The dependence of the magnetic properties $B_{\mathrm{r}}$ and ${ }_{\mathrm{i}} H_{\mathrm{c}}$ of the fabricated sintered magnet on the weight ratio of the inter-additive $\mathrm{CaO} / \mathrm{SiO}_{2}$ added during the fine milling stage.

Fig.9. SEM of the hexaferrite $\mathrm{Ca}_{1-x-y} \mathrm{La}_{x} \mathrm{Sr}_{y} \mathrm{Fe}_{10.9} \mathrm{Co}_{z} \mathrm{O}_{19}(x=0.45, y=0.18)$ magnet calcined at 
$1240^{\circ} \mathrm{C}$ and sintered at $1230^{\circ} \mathrm{C}$. 
Figures

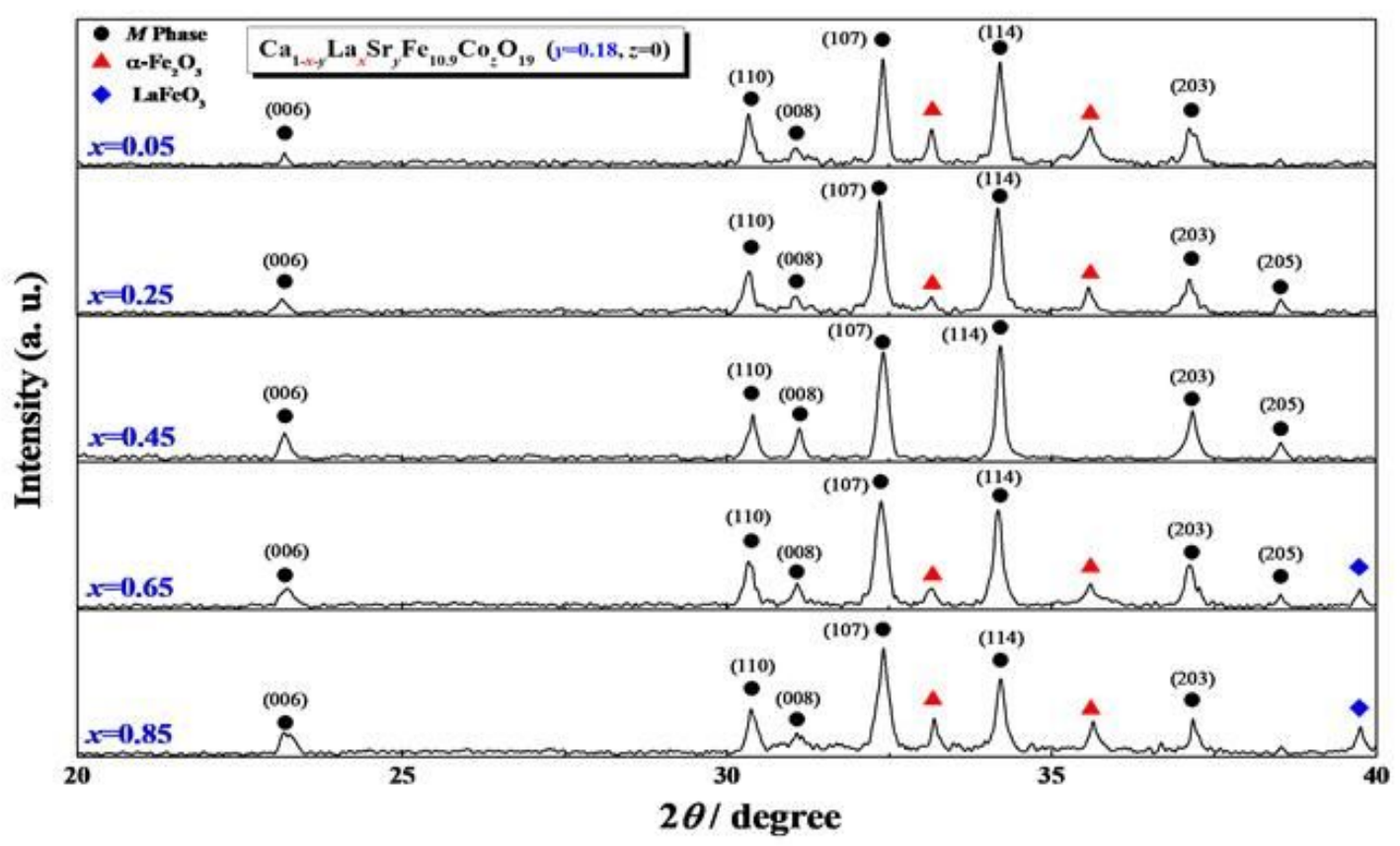

Figure 1

X-ray diffraction patterns of the hexaferrite Ca1-x-yLaxSryFe10.9CozO19 calcined powders with La content (x) from 0.05 to 0.85 , and Ca content (1-x-y). 


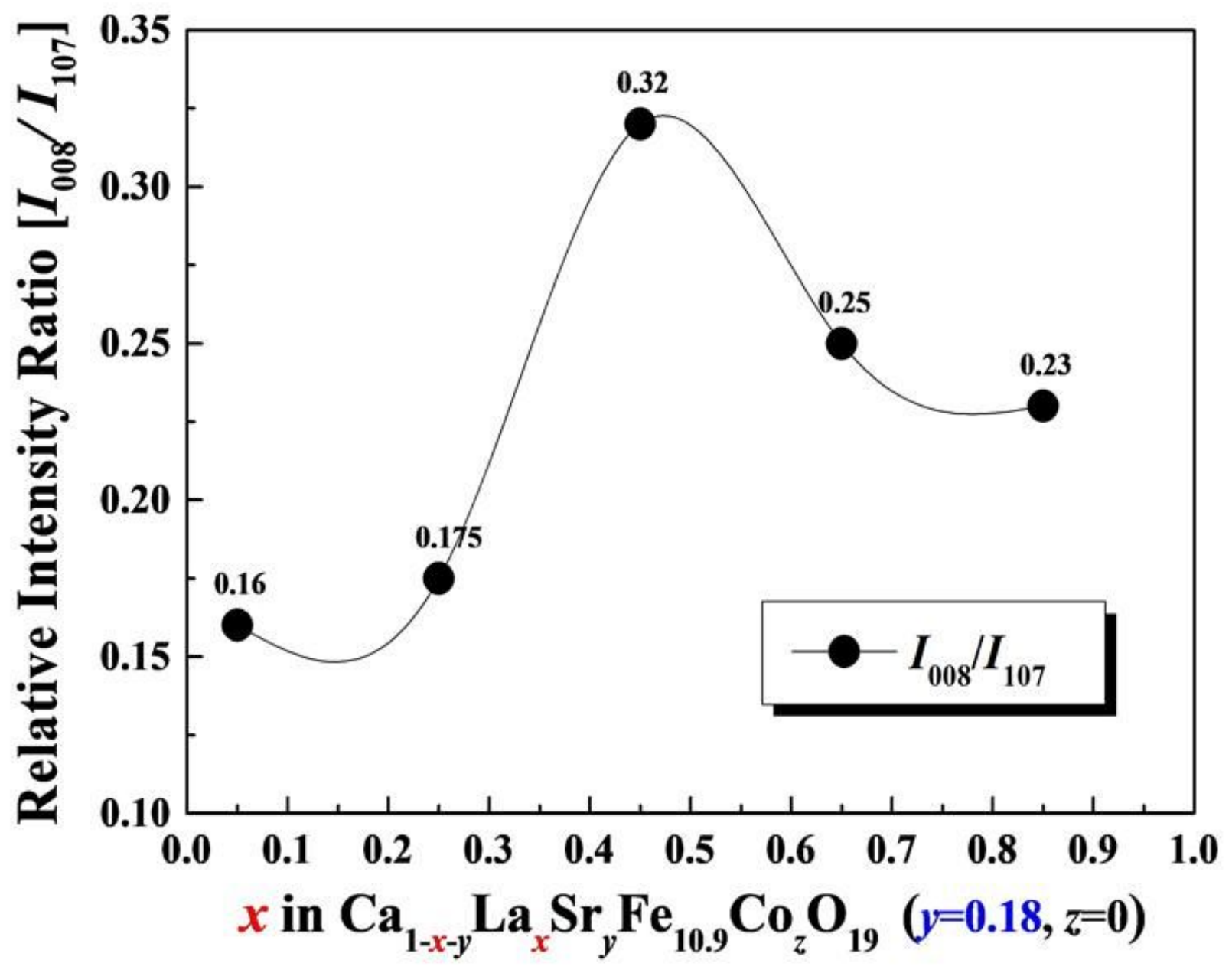

Figure 2

Relative intensity ratio (I008//107) of the hexaferrite Ca1-x-yLaxSryFe10.9CozO19 calcined powders with La content $(\mathrm{x})$ from 0.05 to 0.85 , and Ca content $(1-x-y)$.
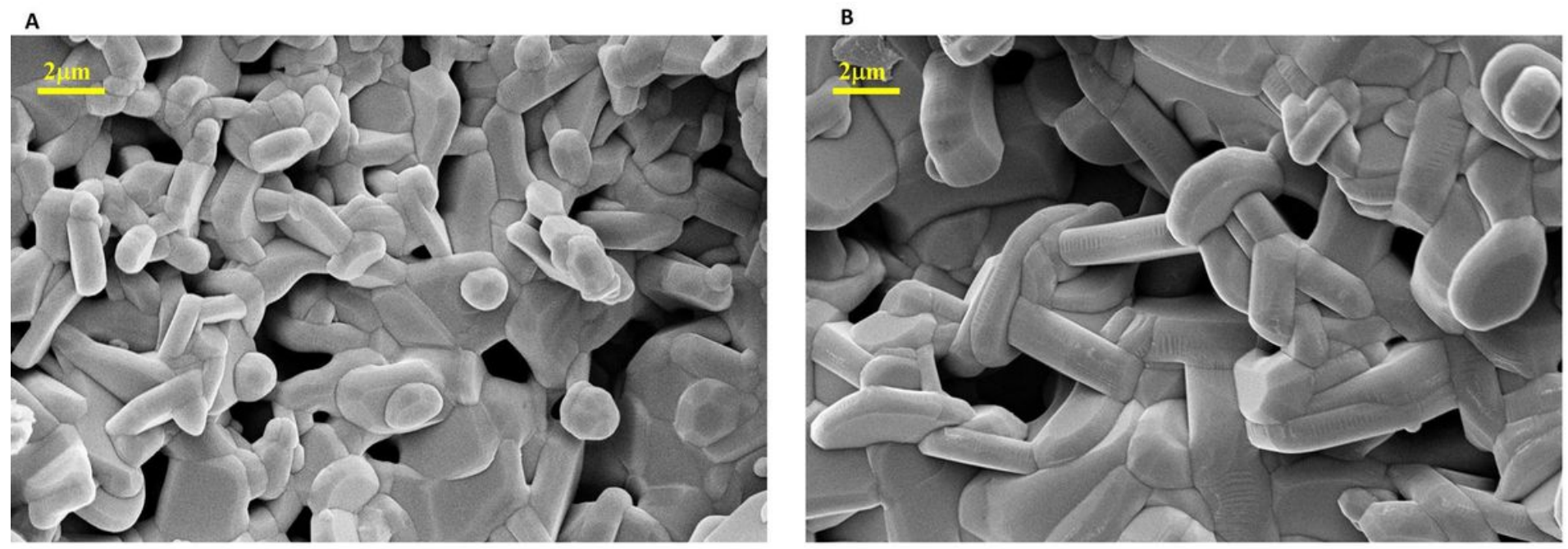
Figure 3

SEM of the hexaferrite Ca1-x-yLaxSryFe10.9 CozO19 calcined powders with Sr content (y) from 0 to 0.18.

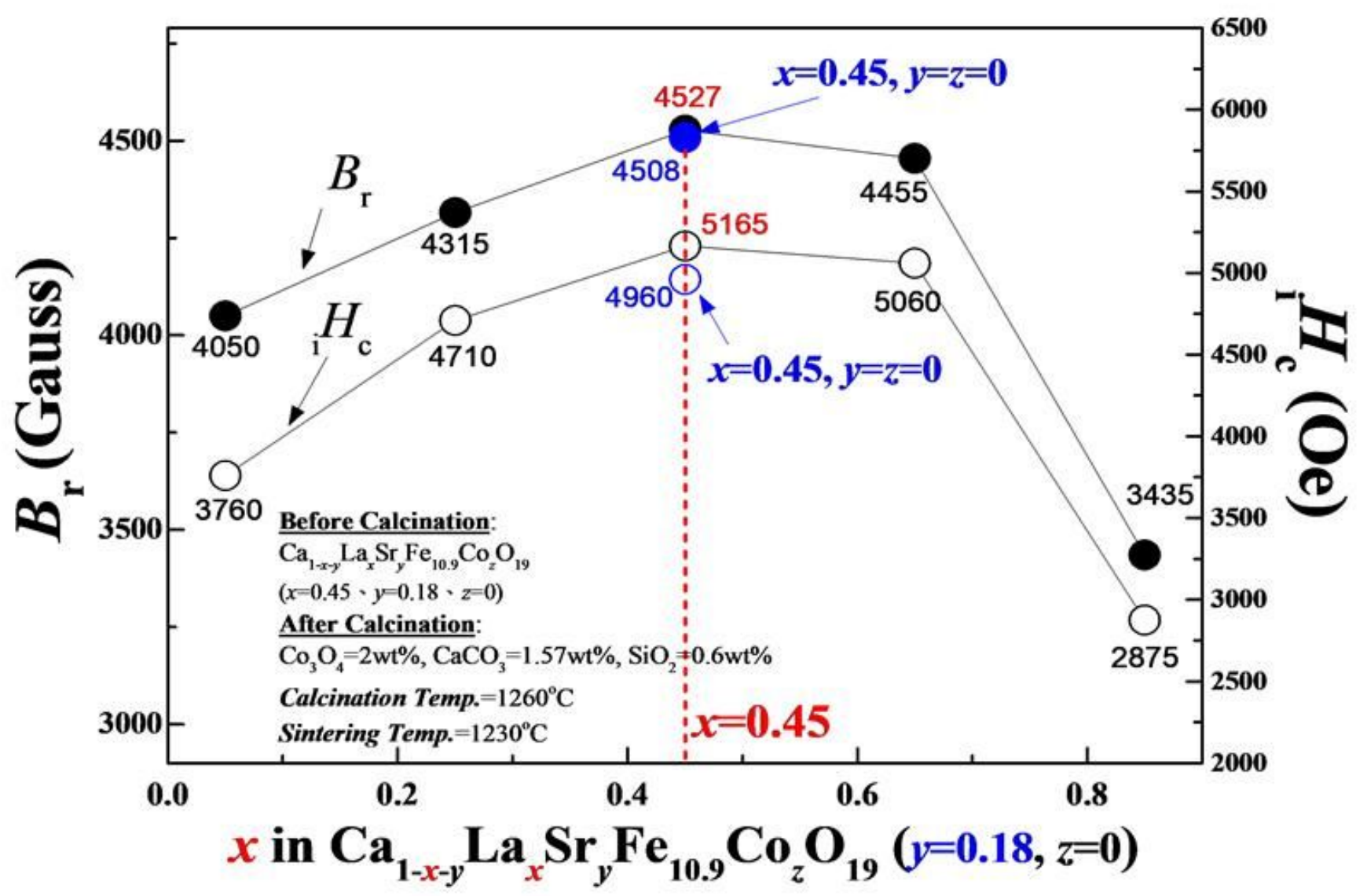

Figure 4

The dependence of the magnetic properties $\mathrm{Br}$ and $\mathrm{iHc}$ of the fabricated sintered magnet on the $\mathrm{x}$ value of the formula Ca1-x-yLaxSryFe10.9CozO19 calcined powder. 


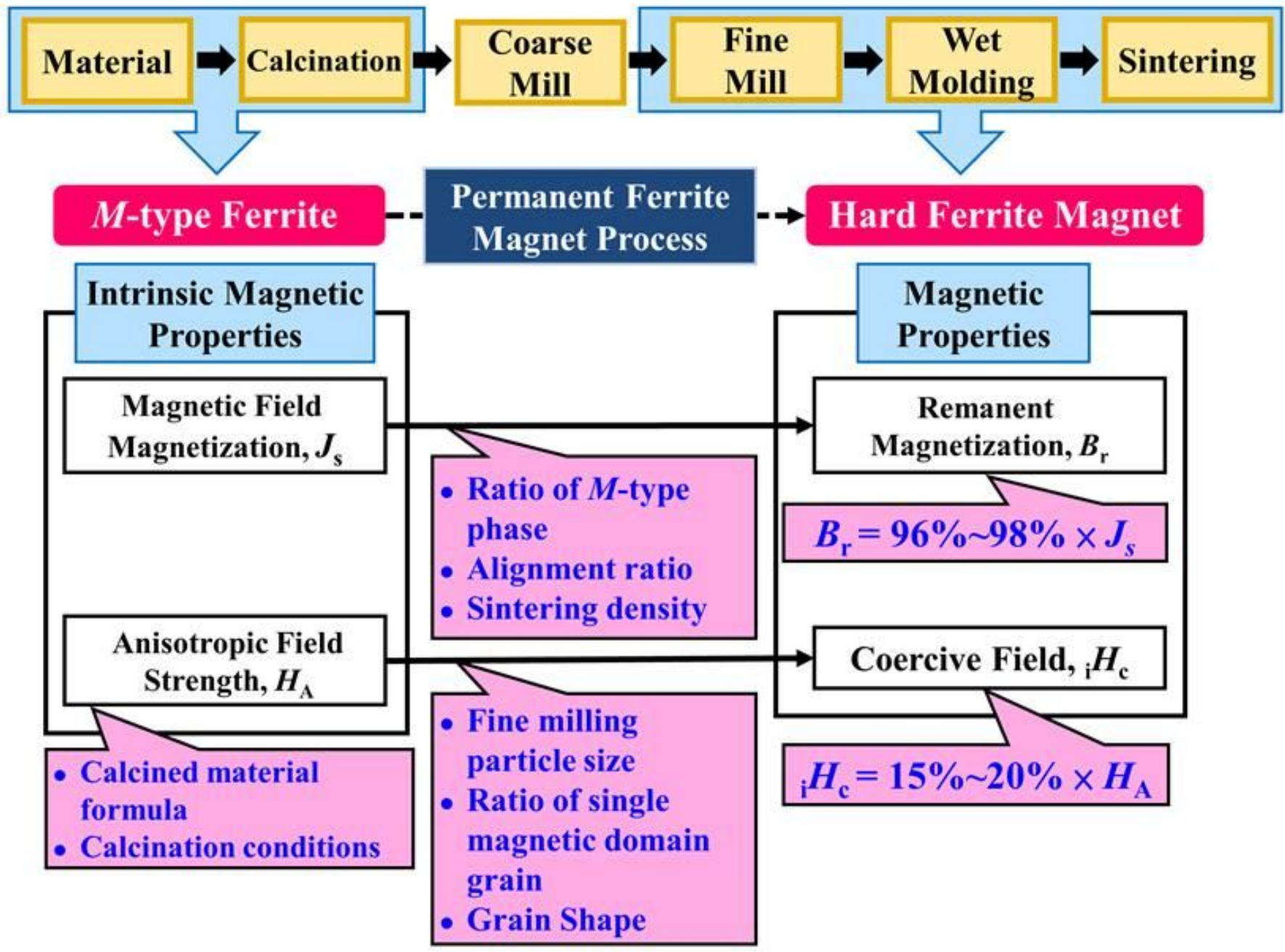

Figure 5

Correlation between magnetic characteristics and related factors in the manufacturing process of permanent ferrite magnets. 


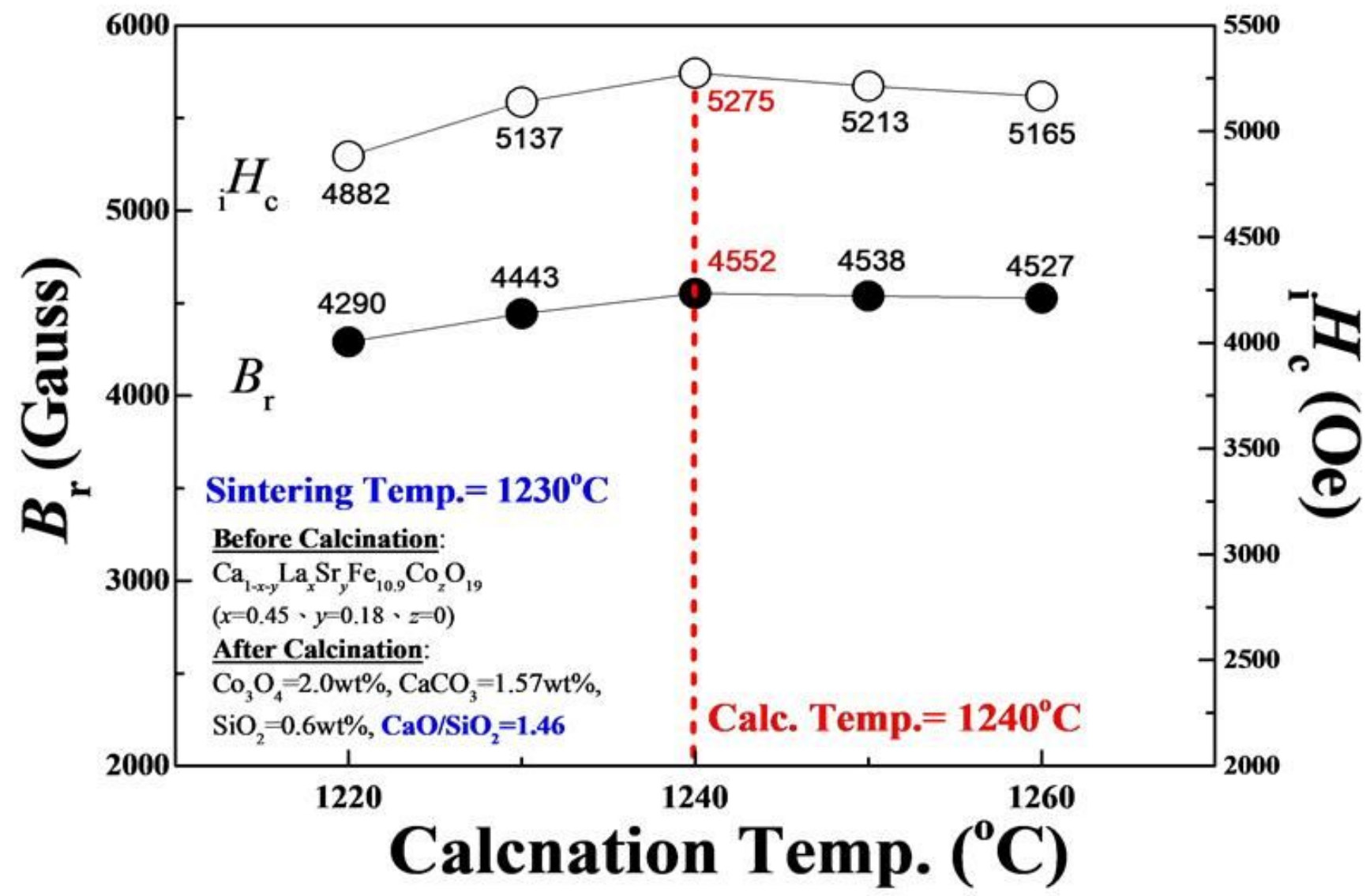

Figure 6

Effect of the calcination temperature on $\mathrm{Br}$ and iHc of the hexaferrite Ca1-x-yLaxSryFe10.9CozO19 $(x=0.45, y=0.18)$ calcined powders. 


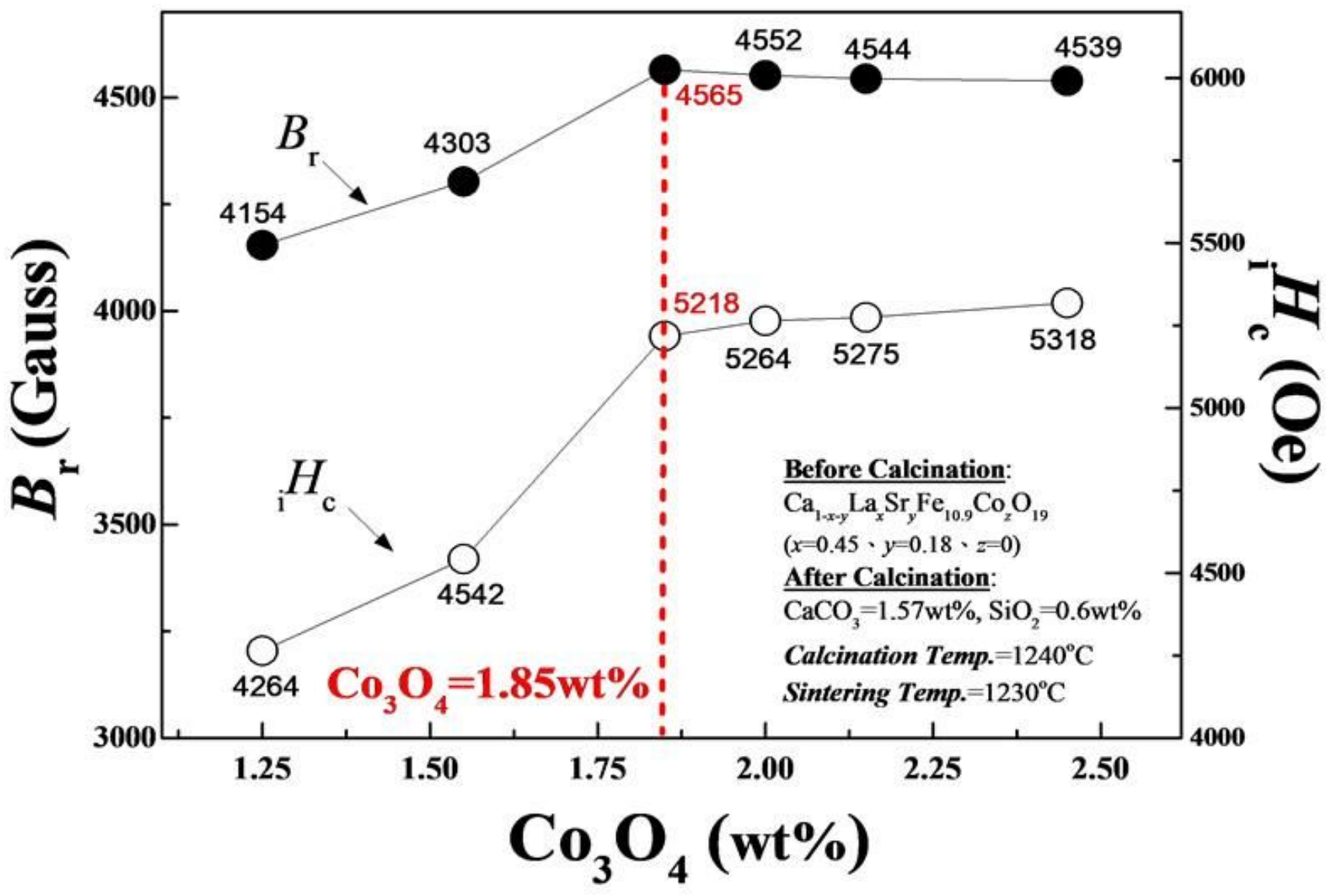

Figure 7

The dependence of the magnetic properties $\mathrm{Br}$ and $\mathrm{iHc}$ of the fabricated sintered magnet on the amount of Co304 added after calcination. 


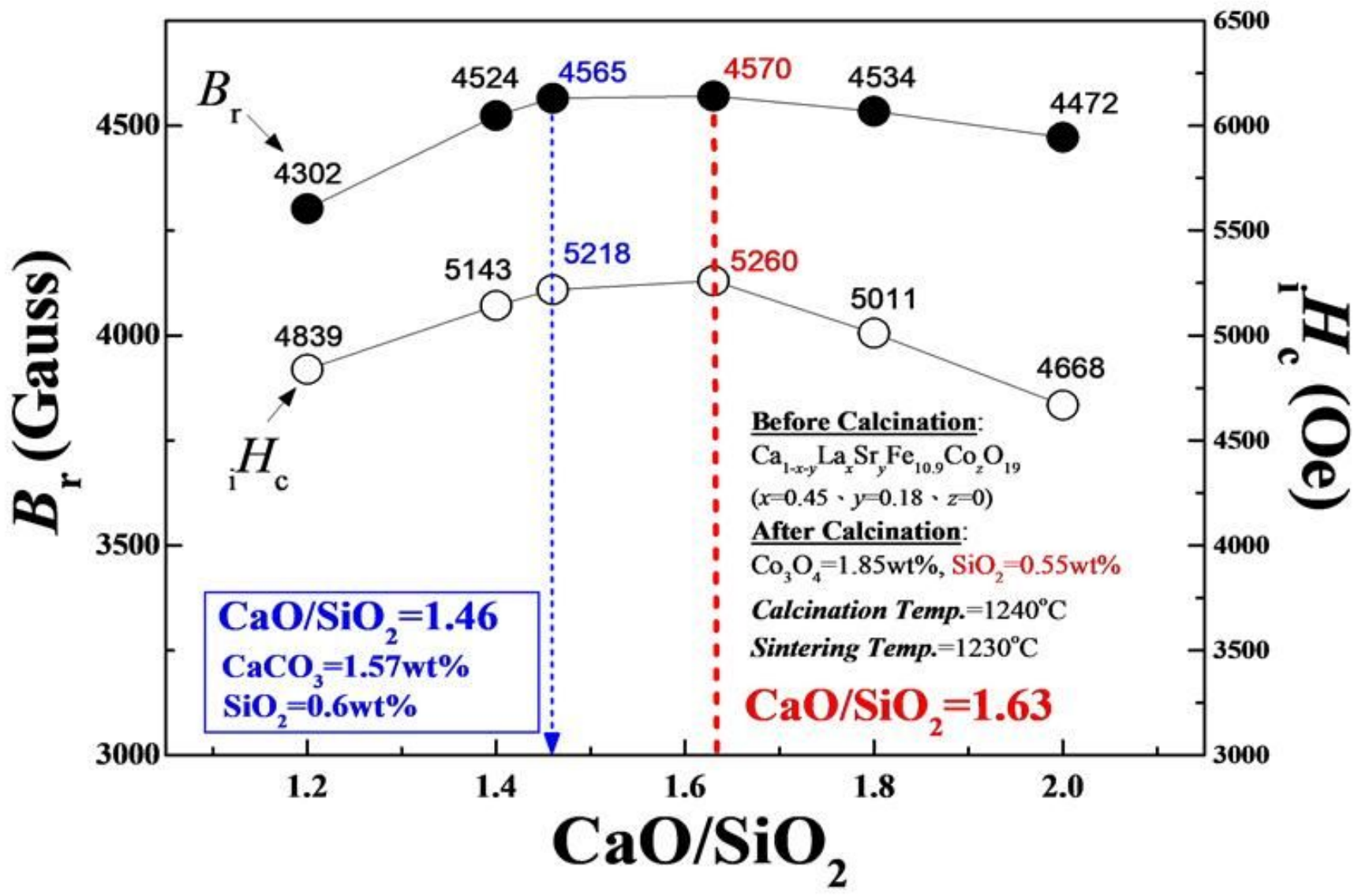

Figure 8

The dependence of the magnetic properties $\mathrm{Br}$ and iHc of the fabricated sintered magnet on the weight ratio of the inter-additive $\mathrm{CaO} / \mathrm{SiO} 2$ added during the fine milling stage. 


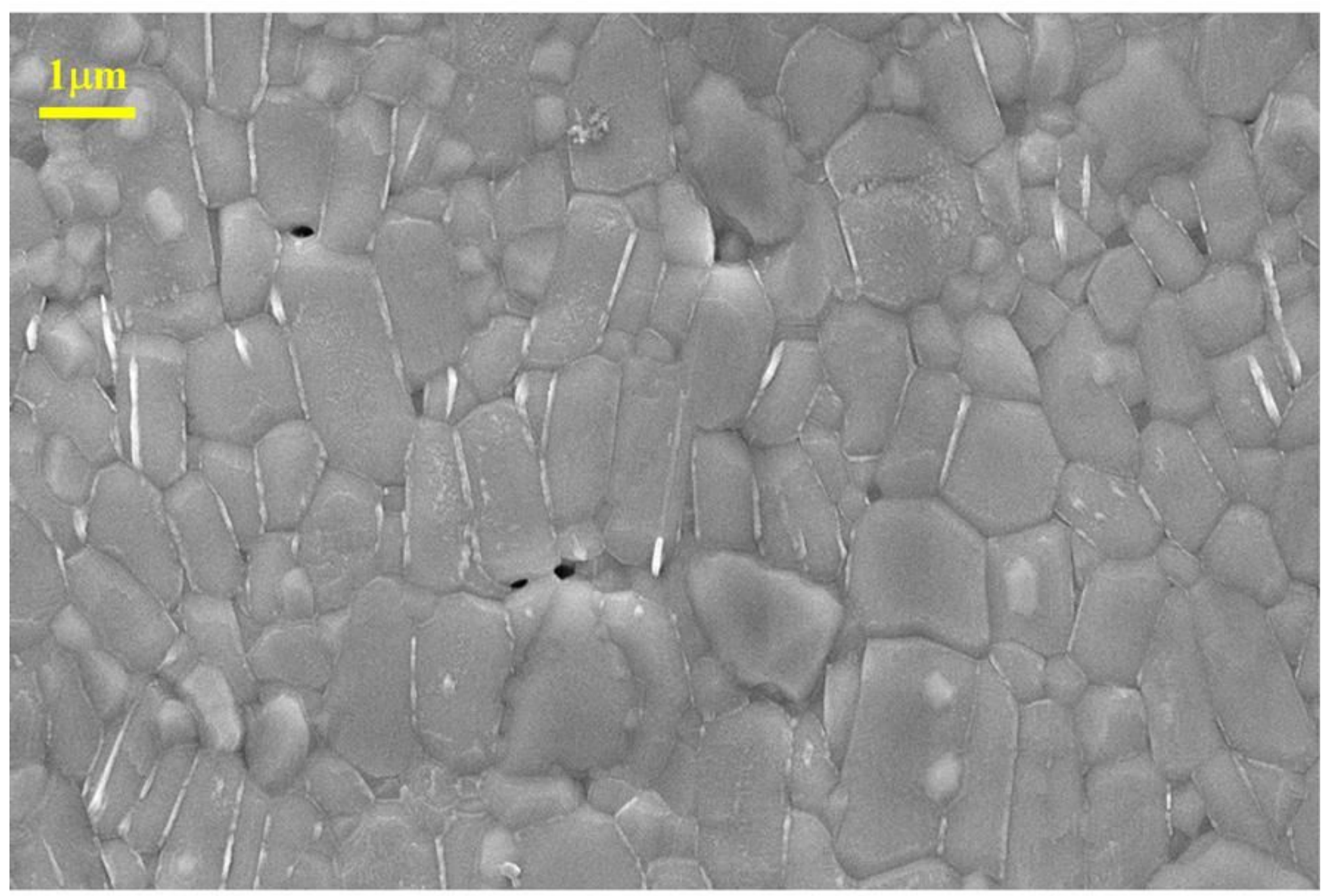

Figure 9

SEM of the hexaferrite Ca1-x-yLaxSryFe10.9CozO19 ( $\mathrm{x}=0.45, \mathrm{y}=0.18)$ magnet calcined at $1240^{\circ} \mathrm{C}$ and sintered at $12300 \mathrm{C}$. 